Haiyyu Darman Moenir| Implementasi ASEAN Tourism Strategic Plan 2011-2015 dalam Kebijakan Pariwisata Indonesia di masa Pemerinatahan Jokowi

\title{
Implementasi ASEAN Tourism Strategic Plan 2011-2015 dalam Kebijakan Pariwisata Indonesia di masa Pemerintahan Jokowi
}

\author{
Haiyyu Darman Moenir * \\ haiyyu_darman@yahoo.com
}

\begin{abstract}
Tourism is one of the important sectors in the economic development of a country. This is evidenced by the revenue contribution of state revenues generated from the tourism sector. Indonesia under the leadership of President Joko Widodo Focused on the development of maritime shaft which one of the main concern is tourism. In the context of tourism, Indonesia has a fairly high appeal at the local and international level. Southeast Asia region incorporated in ASEAN is a good market for Indonesia in attracting the attention of ASEAN people to come and travel in Indonesia. Through joint strategy in regional tourism development, Indonesia is trying to implement ASEAN tourism policy known as ASEAN Tourism Strategic Plan (2011-2015) in domestic context through Indonesian tourism policy. This paper will focus on how the implementation of the ASEAN Tourism Strategic Plan 2011-2015 in the Indonesian Tourism Policy in the Reign of President Joko Widodo.
\end{abstract}

Key words: Tourism, connectivity, policy, government, ASEAN

*Dosen Ilmu Hubungan Internasional Universitas Andalas 
Haiyyu Darman Moenir | Implementasi ASEAN Tourism Strategic Plan 2011-2015 dalam Kebijakan Pariwisata Indonesia di masa Pemerinatahan Jokowi

\section{Pendahuluan}

Dalam beberapa tahun belakangan ini, paradigma pembangunan di sejumlah negara lebih berorientasi pada pengembangan sektor jasa dan industri, termasuk di dalamnya industri pariwisata. Pariwisata muncul sebagai andalan dalam ekonomi masyarakat negara-negara di dunia. Dalam sebuah jurnal yang berjudul "Pariwisata, Pengentasan Kemiskinan, dan MDGs" bahwa industri pariwisata merupakan jantung yang menggerakan roda perekonomian serta menjadi salah satu industri terbesar dan menjadi sektor andalan di dalam pembangunan ekonomi dan penyediaan lapangan pekerjaan. ${ }^{1}$

Pariwisata menjadi andalan ekonomi negara-negara dunia karena salah satu kontribusinya dalam penciptaan lapangan pekerjaan. Adanya pembuktian dari sejumlah data yaitu Data ILO (International Labour Organization $)^{2}$ misalnya, Lesnussa menulis bahwa menurut ILO pada tahun 2011 sektor pariwisata telah menciptakan 244 juta pekerjaan atau 8,7 persen dari

\footnotetext{
${ }^{1}$ H.Wahyudi,"Pariwisata, Pengentasan Kemiskinan, dan MDGs",(UPBJJ-UT Denpasar,2012)

${ }^{2}$ ILO merupakan Organisasi Internasional dibawah PBB yang mengurus bidang perburuhan internasional
}

penyerapan tenaga kerja di dunia. Data ILO ini sejalan dengan hasil kajian World Economic Forum (WEF), ${ }^{3}$ terhadap sektor pariwisata yang menunjukkan bahwa kontribusi sektor ini terhadap PDB dan penyediaan lapangan kerja rata-rata mencapai $9 \%$ setiap tahunnya dengan kenaikan yang sangat positif dari tahun ke tahun. ${ }^{4}$ Untuk kawasan Asia Tenggara, WEF mencatat kontribusi sektor pariwisata mencapai 4,6 persen terhadap DB negaranegara ASEAN dan 10,9 persen . Dampak positif lainnya adalah 9,3 juta orang bekerja di sektor ini dan diperkirakan mencapai 25 juta orang . 5

Dalam tulisan Is Prayini, United Nation World Tourism Organization (UNWTO) ${ }^{6}$ mengungkapkan bahwa selama 6 dekade terakhir pariwisata merupakan

\footnotetext{
3 WEF merupakan lembaga internasional yang berkomitmen untuk meningkatkan keadaan dunia melalui kerjasama publik-swasta dalam semangat kewarganegaraan global.

${ }^{4}$ N.Lesnussa,"Pengaruh Citra Keamanan Nasional Indonesia terhadap Jumlah Wisatawan di Indonesia. (Studi Kasus : Indonesia Visit Year 2008). (Skripsi, Universitas Komputer. 2008)

5 R.Handayani,"Mendongkrak Pariwisata Melalui Ujung Jari",Rumah Aktualisasi (Agustus 2013), http://ririnhandayani.blogspot.com/search?q=mendon gkrak+pariwisata + melalui+ujung+jari. Di akses pada 25 Maret 2014

${ }^{6} \mathrm{UN}-\mathrm{WTO}$ : merupakan organisasi internasional dibawah PBB yang bergerak di bidang pariwisata dunia
} 
Haiyyu Darman Moenir| Implementasi ASEAN Tourism Strategic Plan 2011-2015 dalam Kebijakan Pariwisata Indonesia di masa Pemerinatahan Jokowi

industri yang mengalami pertumbuhan dan perkembangan yang cepat. ${ }^{7}$ Ukuran dari pertumbuhan dan perkembangan pariwisata tersebut dapat dilihat dari jumlah kedatangan wisatawan ke suatu negara ataupun kawasan. Pada tahun 2013, kawasan Asia Pasifik menempati posisi kedua setelah Eropa sebagai wilayah yang banyak dikunjungi oleh wisatawan internasional ${ }^{8}$. UN-WTO menegaskan bahwa Asia merupakan wilayah yang paling berkembang di dunia ${ }^{9}$. Hal tersebut didorong oleh pertumbuhan ekonomi yang baik sehingga diperkirakan pada tahun 2020 Asia dan Pasifik akan tumbuh $5 \%$ per tahun dibandingkan rata-rata pertumbuhan ekonomi dunia 4,1 \%. Lebih lanjut UNWTO memprediksikan pada tahun 2033 Asia akan merebut posisi nomor satu dari Eropa dengan peningkatan yang signifikan $7,2 \%$ setiap tahunnya. ${ }^{10}$ Prediksi ini akan dapat dicapai dengan perencanaan pariwisata yang baik dari masing-masing negara. Sehingga pelaku pariwisata di masing-masing negara Asia mulai

\footnotetext{
${ }^{7}$ Is Prayini,'Pengaruh Destination Branding terhadap Tourist Retention Pada Wisatawan Indonesia yang berkunjung ke Thailand",(Skripsi, Universitas Pendidikan Indonesia. 2013)

${ }^{8}$ Ibid

${ }^{9}$ Ibid

${ }^{10}$ I.Prayini,hal 3
}

mempersiapkan perencanaan pariwisata yang matang dan terarah guna menarik wisatawan internasional untuk berkunjung ke negaranya masing-masing.

Wilayah Asia Tenggara dengan wadah organisasi regional ASEAN memiliki potensi yang besar untuk menjadi sebuah kawasan pariwisata yang banyak diminati oleh turis-turis baik lokal, regional maupun internasional. Untuk kawasan Asia Pasifik, UN-WTO mengungkapkan bahwa Asia Tenggara merupakan wilayah yang memiliki kunjungan wisatawan internasional terbesar di Asia ${ }^{11}$. Kontribusi tersebut juga berasal dari wisatawan yang berkunjung ke Indonesia sebagai bagian dari kawasan Asia Tenggara. Dalam tulisan Lesnussa, UNWTO juga mengungkapkan bahwa Indonesia diprediksikan oleh WTO (World Tourism Organization) pada tahun 2010 akan mengalami pertumbuhan 4,2\% per tahun dalam prospek industri pariwisatanya. $^{12}$

Sebagai negara yang berada di wilayah regional Asia Tenggara, Indonesia ${ }^{11}$ Ibid
${ }^{12}$ Nurhayati Lesnussa,'Pengaruh Citra Keamanan
Nasional Indonesia terhadap Jumlah Wisatawan di
Indonesia (Studi Kasus : Indonesia Visit Year 2008
)",2009.hal 1. 
Haiyyu Darman Moenir | Implementasi ASEAN Tourism Strategic Plan 2011-2015 dalam Kebijakan Pariwisata Indonesia di masa Pemerinatahan Jokowi

tergabung dalam Association of South East Asian Nation (ASEAN) yang merupakan organisasi intra kawasan di Asia Tenggara yang beranggotakan sepuluh negara dengan total penduduk 600 juta orang, GDP 2,2 triliun US dollar, dan total perdagangan 678,2 triliun US dollar. ${ }^{13}$ Pada tingkat ASEAN, dalam perjalanannya pada tahun 2015 yang lalu dibentuklah Komunitas ASEAN yang bertujuan untuk lebih mempererat integrasi ASEAN dalam menghadapi perkembangan konstelasi politik internasional. ASEAN menyadari sepenuhnya bahwa keperluan untuk menyesuaikan cara pandang, agar dapat lebih terbuka dalam menghadapi permasalahan-permasalahan internal dan eksternal, serta meningkatkan solidaritas, kohesivitas dan efektifitas kerjasama menjadi suatu hal yang penting. ASEAN yang pada awalnya hanya terfokus pada kerjasama ekonomi, mulai meningkatkan kerjasama lainnya dalam bidang politik keamanan dan sosial budaya. Hal inilah yang kemudian mendasari pembentukan Komunitas ASEAN 2015, yang dilandasi oleh tiga pilar, yaitu ASEAN Political

\footnotetext{
${ }^{13} \mathrm{http}$ ://www.asean.org/images/2013/resources/public ation/Infrastructure_investor.pdf di download tanggal 28 Juni 2013
}

Security Community, ASEAN Economic Community, dan ASEAN Socio-Cultural Community. ${ }^{14}$

Sebagai bagian dari perwujudan Komunitas ASEAN 2015, komunitas yang pada awalnya akan direncanakan pada tahun 2020 ini, dipercepat pelaksanaannya menjadi tahun 2015 yang diresmikan melalui Cebu Declaration on the Acceleration of the Establishment of an ASEAN Community by 2015, pada KTT ke12 ASEAN di Cebu Filipina pada Januari 2007. Oleh karena itu, agar dapat mempercepat terbentuknya ASEAN yang terhubung dengan baik, yang akan berkontribusi secara lebih kompetitif dan kuat, serta dapat membawa orang-orang, barang, dan modal menjadi lebih terintegrasi bersama, maka dibentuklah sebuah gagasan untuk sebuah program yang disebut $A S E A N$ Connectivity. ${ }^{15}$

\section{ASEAN Connectivity atau Konektivitas} ASEAN adalah istilah yang digunakan untuk keterhubungan fisik, lembaga, dan individu yang akan memfasilitasi arus modal, barang, jasa, dan orang-orang di

\footnotetext{
${ }^{14}$ Lihat Buku ASEAN Selayang Pandang, Hal. 1

15 BPPK ASPASAF, "ASEAN Connectivity in Indonesian Context," Jakarta, Kementerian Luar Negeri Republik Indonesia, 2011, hal 1.
} 
Haiyyu Darman Moenir | Implementasi ASEAN Tourism Strategic Plan 2011-2015 dalam Kebijakan Pariwisata Indonesia di masa Pemerinatahan Jokowi

wilayah tersebut untuk mencapai basis perekonomian besar di Asia Selatan pembangunan ekonomi yang lebih besar, memfasilitasi masalah keamanan dan politik, dan mendukung inisiatif sosial dan budaya dalam rangka realisasi Komunitas ASEAN 2015. Ide Konektivitas ASEAN sendiri pertama kali diperkenalkan oleh Perdana Menteri Thailand, Abhisit Vejjajiva pada acara pembukaan pertemuan Menteri Luar Negeri ASEAN ke-42, pada 20 Juli 2009 di Phuket. Sebagai ketua ASEAN, Perdana Menteri Abhisit mengusulkan bahwa sebuah "konektivitas komunitas" harus menjadi salah satu tujuan dari ASEAN Community $2015 .^{16}$

Oleh karena itu, dalam mewujudkan Komunitas ASEAN 2015, ASEAN yang terintegrasi sepenuhnya secara ekonomi sebagai pasar tunggal dan basis produksi harus memiliki konektivitas yang baik dalam seluruh aspek, baik fisik maupun institusi. Selain itu, diharapkan bahwa melalui komunitas yang terhubung dengan baik, ASEAN dapat merealisasikan potensi ekonominya secara maksimal dan juga mendapatkan keuntungan maksimum dari lokasi strategis yang menghubungkan dua

${ }^{16}$ Ibid. Andalas Journal of International Studies | Vol 6 No 1 Mei Tahun 2017

${ }^{17}$ Fandy Meirizma Primayoga, "Analisis Kebijakan Indonesia Terkait Dukungan Terhadap ASEAN Insfrastruktur Fund Sebagai Upaya Persiapan Pelaksanaan ASEAN Economic Community 2015," Jurusan Ilmu Hubungan Internasional, Universitas Brawijaya, hal 2-3.

ASEAN dan proses pembentukan komunitas, serta meningkatkan daya saing ASEAN, mempromosikan pemahaman sosial dan budaya, memperlancar mobilitas sebuah Master Plan on ASEAN Connectivity (MPAC), yang berisi mengenai dokumen strategis untuk mencapai Konektivitas ASEAN yang maksimal dan perencanaan implementasi untuk periode 2011-2015, yang bertujuan untuk menghubungkan ASEAN melalui peningkatan konektivitas fisik atau pembangunan infrastruktur, penghubungan konektivitas antar institusi, dan keterhubungan sumber daya manusia. Selain itu, Konekivitas ASEAN juga bertujuan untuk mendorong pertumbuhan ekonomi, memperkecil jarak pembangunan antar negara, mempercepat integrasi sosial dan budaya, memperlancar mobilitas

Dalam pelaksanaan Konektivitas ASEAN, para pemimpin ASEAN menyusun

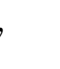


Haiyyu Darman Moenir | Implementasi ASEAN Tourism Strategic Plan 2011-2015 dalam Kebijakan Pariwisata Indonesia di masa Pemerinatahan Jokowi

manusia, dan menghubungkan negaranegara anggotanya dengan dunia luar. ${ }^{18}$

Pembentukan masyarakat ASEAN sebagai sebuah cita-cita bersama negaranegara di Asia Tenggara mendasarkan pada tiga pilar yaitu ASEAN Economic Community (AEC), ASEAN Security Community (ASC), dan ASEAN SocioCultural Community (ASCC). Sebagai panduan, di susunlah Master Plan tentang ASEAN Connectivity yang berisi tentang target pencapaian dan juga hambatan yang berpotensi mengganggu terwujudnya ASEAN Community 2015. Pelaksanaan kegiatan yang tercantum dalam Master Plan ini mempunyai kurun waktu 2011-2015 dimana dalam periode tersebut terdapat strategi untuk menghubungkan ASEAN menjadi lebih erat yaitu meliputi physichal connectivity meliputi meningkatkan pembangunan infrastruktur fisik, institusional connectivity mencakup institusi yang efektif, proses dan mekanismenya serta people-to-people connectivity yaitu meningkatkan interaksi antar warga negara di negara-negara ASEAN.

Konektivitas ASEAN yang berfokus pada people-to-people connectivity dilakukan salah satunya melalui sektor pariwisata. Melalui sektor ini, pergerakan orang-orang intra ASEAN dapat ditingkatkan. Kunjungan warga ASEAN ke salah satu negara anggota ASEAN menunjukkan jumlah yang besar. Jumlah kunjungan wisatawan ke ASEAN tahun 2012 mencapai 74,8 juta orang dimana jumlah meningkat dari 10,14 persen dibandingkan dengan tahun 2011, dan sekitar 23 persen adalah warga intra ASEAN. ${ }^{19}$ Peningkatan ini salah satunya dipengaruhi oleh kebijakan tentang kemudahan untuk memasuki sebuah negara tanpa menggunakan visa bagi warga negara di negara-negara ASEAN dan tiket penerbangan yang murah.

Skema sederhana dari ide Konektivitas ASEAN dapat dirujuk dalam diagram berikut:

$\overline{{ }^{18} \mathrm{Ibid} .}$

${ }^{19}$ Kompas, 22 Januari 2013

Andalas Journal of International Studies | Vol 6 No 1 Mei Tahun 2017 
Haiyyu Darman Moenir | Implementasi ASEAN Tourism Strategic Plan 2011-2015 dalam Kebijakan Pariwisata Indonesia di masa Pemerinatahan Jokowi

Skema 1

ASEAN Connectivity

ASEAN Connectivity Development

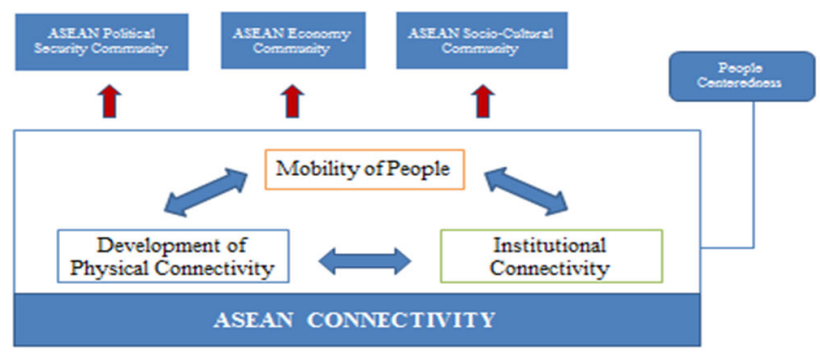

Pariwisata merupakan sektor strategis yang dapat meningkatkan devisa negara dan memberikan implikasi yang signifikan bagi perekonomian negara tersebut. Melihat banyaknya benefit yang dihasilkan sektor pariwisata tersebut, ASEAN berupaya untuk lebih mengintegrasikan konektivitas antar negara-negara anggota agar memudahkan akses pariwisata kawasan, sehingga dapat memupuk keuntungan yang lebih besar.

Konektivitas menjadi salah satu elemen penting bagi ASEAN guna memajukan pariwisata di kawasan tersebut. Hal ini terlihat dari pengangkatan banyak isu konektivitas dalam beberapa agenda kegiatan ASEAN. Misalnya, dalam ASEAN Community 2015, isu transportasi mulai dibahas melalui pertemuan atau forum khusus seperti ASEAN Transport Minister Meeting dan pembentukan ASEAN Tourism Forum (ATF). Selain itu, ASEAN juga mengeluarkan blueprint yang berjudul ASEAN Tourism Strategic Plan 2011 - 2015 (ATSP) yang didalamnya juga membahas isu transportasi untuk menunjang perkembangan pariwisata di ASEAN. ATSP adalah landasan dari ASEAN Tourism Marketing Strategy (ATMS) 2012-2015, yang diadopsi oleh menteri-menteri pariwisata ASEAN pada Januari 2012.Rencana strategis ini merupakan rencana yang disusun oleh organisasi pariwisata nasional negara-negara ASEAN untuk mencapai tujuan di tahun 2015 yaitu menjaga pertumbuhan pariwisata di atas dua digit. $^{20}$

Indonesia, sebagai satu-satunya negara ASEAN yang memiliki sumber daya alam yang signifikan dan memiliki lingkungan budaya yang sangat kompleks, pelaksanaan Konektivitas ASEAN menjadi tantangan tersendiri bagi Indonesia dalam merealisasikan Komunitas ASEAN 2015.

${ }^{20}$ Tourism Strategic Plan 2011 - 2015 ASEAN,16. Aug 2012 , http://www.resonanceco.com/Library/tourismstrategic-plan-2011-2015/ 16 Mei 2014

\begin{tabular}{|l|l} 
Andalas Journal of International Studies | Vol 6 No 1 Mei Tahun 2017 & 63
\end{tabular} 
Haiyyu Darman Moenir | Implementasi ASEAN Tourism Strategic Plan 2011-2015 dalam Kebijakan Pariwisata Indonesia di masa Pemerinatahan Jokowi

Tabel 1

Indonesia: Penduduk, Wilayah dan Ekonomi 2010

\begin{tabular}{|c|c|c|c|c|c|c|}
\hline \multirow{3}{*}{$\mathrm{ra}^{\mathrm{Neg}}$} & \multirow{3}{*}{$\begin{array}{c}\text { otal } \\
\text { Luas } \\
\text { Wilay } \\
\text { ah } \\
\text { sq. } \\
\text { km) }\end{array}$} & \multirow{3}{*}{$\begin{array}{c}\text { Total } \\
\text { Populasi } \\
\text { (Ribu } \\
\text { an) }\end{array}$} & \multicolumn{4}{|c|}{$\begin{array}{l}\text { Gross Domestic } \\
\text { Product (GDP) }\end{array}$} \\
\hline & & & \multicolumn{2}{|c|}{$\begin{array}{r}\text { har } \\
\text { ga saat ini }\end{array}$} & \multicolumn{2}{|c|}{$\begin{array}{r}\text { pe } \\
\text { rcapita }\end{array}$} \\
\hline & & & $\begin{array}{l}\text { US\$ } \\
\mathrm{Mn})\end{array}$ & $\begin{array}{l}\text { PP } \\
\text { P\$ } \\
\text { M } \\
\text { n) }\end{array}$ & $\begin{array}{l}\text { US } \\
\$)\end{array}$ & $\begin{array}{l}\text { PPP } \\
\$)\end{array}$ \\
\hline $\begin{array}{l}\text { ndo } \\
\text { nesi } \\
\text { a }\end{array}$ & $\begin{array}{c}, 860 \\
360\end{array}$ & $\begin{array}{l}234,1 \\
81\end{array}$ & $\begin{array}{c}08,0 \\
32\end{array}$ & $\begin{array}{l}, 03 \\
0,9 \\
98\end{array}$ & $\begin{array}{l}, 02 \\
3\end{array}$ & $\begin{array}{l}, 40 \\
3\end{array}$ \\
\hline
\end{tabular}

Sumber: ASEAN Finance and Macroeconomic Surveillance Database and IMF-World Economic Outlook April 2011

\section{Sebagai dampak diberlakukannya} integrasi ASEAN pada akhir tahun 2015 yang lalu, sebagian besar wilayahnya berada dalam Negara Kesatuan Republik Indonesia. Dan karena Konektivitas ASEAN adalah keputusan kolektif Pemimpin ASEAN, maka Indonesia memiliki kewajiban untuk ikut serta dalam menyukseskan hal ini. Namun karena kondisi geografis Indonesia yang terdiri dari ribuan pulau, tugas terbesar dalam menghubungkan kawasan ASEAN berada di pundak Indonesia.

Semenjak Jokowi terpilih menjadi Presiden Republik Indonesia pada tahun 2014, Presiden Jokowi meluncurkan Kebijakan Poros Maritim, dimana hal ini menjadi dasar dari kebijakan luar negeri
Indonesia. ${ }^{21}$ Hal ini menjadi perhatian yang menarik untuk melihat bagaimana implementasi kebijakan pemerintah Presiden Jokowi yang berfokus pada isu maritim terhadap pengembangan pariwisata Indonesia dalam menghadapai pelaksanaan Konektivitas ASEAN yang telah diberlakukan pada tahun 2015 yang lalu yang didasarkan pada Asean Tourism Strategic Plan.

\section{Pariwisata Dalam Konteks Asean}

Pariwisata dalam pendefinisian United Nations World Tourism Organization (UNWTO) adalah sebuah fenomena sosial,budaya dan ekonomi yang menyebabkan perpidahan orang ke suatu negara atau tempat yang bukan daerah asalnya dengan tujuan personal ataupun professional serta bisnis. ${ }^{22}$ Pariwisata dipercaya sebagai sebuah industri yang mampu tumbuh dan berkembang secara cepat. ${ }^{23}$ Negara-negara anggota ASEAN

\footnotetext{
${ }^{21}$ Jokowi Sebar Ide Poros Maritim di KTT ASEAN, http://www.cnnindonesia.com/ekonomi/2014111312 2827-92-11279/jokowi-sebar-ide-poros-maritim-diktt-asean/, diakses pada 16 Maret 2016.

${ }^{22} \mathrm{UNWTO}$, www.unwto.org diakses pada 13 Oktober 2016 pada pukul 22.05 WIB

${ }^{23}$ Vannarith chheang," Tourism and Regional Integrastion in Southeast Asia",Tokyo,IDEJETRO:2013, Hal 13
} 
Haiyyu Darman Moenir| Implementasi ASEAN Tourism Strategic Plan 2011-2015 dalam Kebijakan Pariwisata Indonesia di masa Pemerinatahan Jokowi

merupakan actor yang cukup aktraktif dalam potensi tujuan wisata didunia. ${ }^{24}$

Pariwisata dalam konteks ASEAN memliki cara pandang yang cukup berbeda dari negara-negara atau kawasan-kawasan lainnya. Hal ini dibuktikan dengan promosi pariwisata yang dilakukan selama ini bukan hanya dititik beratkan pada pembangunan dan pengembangan ekonomi saja, akan tetapi juga pada pengenalan terhadap idiologi dan symbol dari identitas dan etnik. $^{25}$

Peningkatan sektor pariwisata di negara-negara ASEAN menjadi salah satu prioritas para anggota. Kepedulian akan bidang pariwisata yang berkemungkinan besar mampu memberikan pemasukan besar bagi negara-negara ASEAN ditunjukan dengan pembentukan Sub-Committee of Tourism (SCOT) dibawah komite ASEAN yang menangani masalah perdagangan dan pariwisata. SCOT ini dibentuk pada tahun 1976 dengan tujuan dasar untuk memluai pengembangan pada sektor pariwisata

${ }^{24}$ Ibid, Hal 13

${ }^{25}$ Sofield, "Rethinking and reconceptualizing social and culture in southeast and south asian tourism development", Oxford,Butterworth Heinemann:2000,Hal 15 regional dalam bidang promosi, pemasaranm, serta penelitian. ${ }^{26}$

Pengembangan mengenai sektor pariwisata ASEAN berlanjut dengan dibentuknya sebuah pertemuan yang berguna untuk mendorong kepariwisataan negara-negara ASEAN untuk terus maju dan berkembang. Pertemuan ini diberi nama ASEAN Tourism Forum (ATF) di Genting Highland, Malaysia pada tahun $1981 .{ }^{27}$ ATF secara definisi adalah sebuah kerjasama regional yang berupaya mempromosikan wilayah ASEAN sebagai salah satu tujuan wisatawan. Dalam pembentukannya, ATF memiliki 5 tujuan mendasar. Tujuan-tujuan tersebut meliputi;

1. Mempromosikan ASEAN sebagai tujuan yang atraktif di berbagai sisi;

2. menciptakan dan meningkatkan kesadaran bahwa ASEAN sebagai kawasan tujuan turis yang kompetitif dikawasan asia pasifik;

3. menarik lebih banyak turis untuk datang ke masing-masing negara ASEAN;

\footnotetext{
${ }^{26}$ Plan of action on ASEAN Cooperation in tourism. http://asean.org/?static post=plan-of-action-onasean-cooperation-in-tourism diakses pada 14 oktober 2016 pada pukul 00.10 wib

${ }^{27}$ Lady Amalia, Efektivitas ASEAN Torism Strategic Plan 2011-2015 di Indonesia, Jurnal Analisis

Hubungan Internasional, Vol. 5 No. 1, Februari 2016, Hal 258
} 
Haiyyu Darman Moenir | Implementasi ASEAN Tourism Strategic Plan 2011-2015 dalam Kebijakan Pariwisata Indonesia di masa Pemerinatahan Jokowi

4. Mempromosikan perjalanan internal ASEAN;

5. Memperkuat kerjasama antar sektor dalam indusri pariwisata ASEAN. ${ }^{28}$

Pada awal pembentukan ASEAN Torism Forum, acuan pengembangan pariwisata negara-negara ASEAN didasarkan kepada Roadmap for Integration of Tourism Sector (RITS) yang dimulai pada tahun 2015 hingga $2010 .{ }^{29}$ Dalam perjalanan waktu, disusun sebuah strategi baru yang semakin efektif dalam peningkatan sektor pariwisata negara-negara ASEAN. Hal ini ditunjukkan dengan Penigkatan pengembangan kerjasama mengenai pariwisata di negara-negara ASEAN semakin menunjukkan keseriusan dimana pada pertemuan ke-10 ATF di Brunei Darussalam, disepakati sebuah rencana kerja jangka panjang mengenai pariwisata ASEAN. Kesepakatan jangka panjang ini dikenal dengan ASEAN Tourism Strategic Plan (ATSP) 2011-2015.

ATSP 2011-2015 ini berujuan untuk membangun sebuah blueprint terkait dengan

\footnotetext{
${ }^{28}$ http://www.atfcambodia.com/atfobjective.php Diakses pada 14 oktober 2016 pada pukul 00.25 wib ${ }^{29}$ Lady Amalia, Efektivitas ASEAN Torism Strategic Plan 2011-2015 di Indonesia, Jurnal Analisis Hubungan Internasional, Vol. 5 No. 1, Februari 2016, Hal 258
}

kebijakan, produk, dan proyek dalam arena pemasaran, pengembangan produk, standar, pengembangan sumber daya manusia, investasi dan komunikasi antar negara ASEAN. ${ }^{30}$ ATSP ini juga nantinya diharapkan mampu untuk dikembangkan dalam bentuk implementasi lokal bagi negar-negara ASEAN guna penigkatan nilai tawar dibidang pariwisata agar mampu memberikan kontribusi peningkatan pemasukan bagi negara masing-masing. ${ }^{31}$

Rencana strategi pariwisata ASEAN atau ATSP 2011-2015 yang dibentuk melalui ASEAN Regional Forum meliputi 3 arahan strategi dasar. Arahan Strategi tersebut meliputi;

\section{Pengembangan produk-produk} kawasan yang eksperiensial dan pemasaran kreatif serta strategi investasi;

Pengembangan Produk-produk kawasan dan pemasaran serta strategi investasi merupakan arahan strategi pertama dalam mengembangkan pariwisata dikawasan ASEAN. Arahan ini akan

\footnotetext{
${ }^{30}$ Memanfaatkan kerjasama pariwisata ASEAN untuk mendorong industri pariwisata Indonesia http://www.kemenkeu.go.id/sites/default/files/Asean \%20Tourism_Suska\%20\&\%20Yuventus\%20Effendi. pdf diakses pada 14 oktober 2016 pada pukul 00.45 wib ${ }^{31}$ Ibid
} 
Haiyyu Darman Moenir | Implementasi ASEAN Tourism Strategic Plan 2011-2015 dalam Kebijakan Pariwisata Indonesia di masa Pemerinatahan Jokowi

diimplementasikan dalam aksi strategis yang akan mendukung terciptanya tujuan dari rencana strategi ini dibuat. Pada arahan strategi pertama, ditemukan setidaknya ada tiga aksi strategi yang akan dilakukan. ketiga hal tersebut meliputi;

1. Pengembangan dan penerapan strategi pemasaran pariwisata untuk wilayah ASEAN;

2. Pengembangan paket wisata kawasan atau sub-kawasan;

3. Peningkatan kebijakan hubungan eksternal dan prosedur pariwisata ASEAN. $^{32}$

Pemaparan ini tergambar jelas pada table berikut:

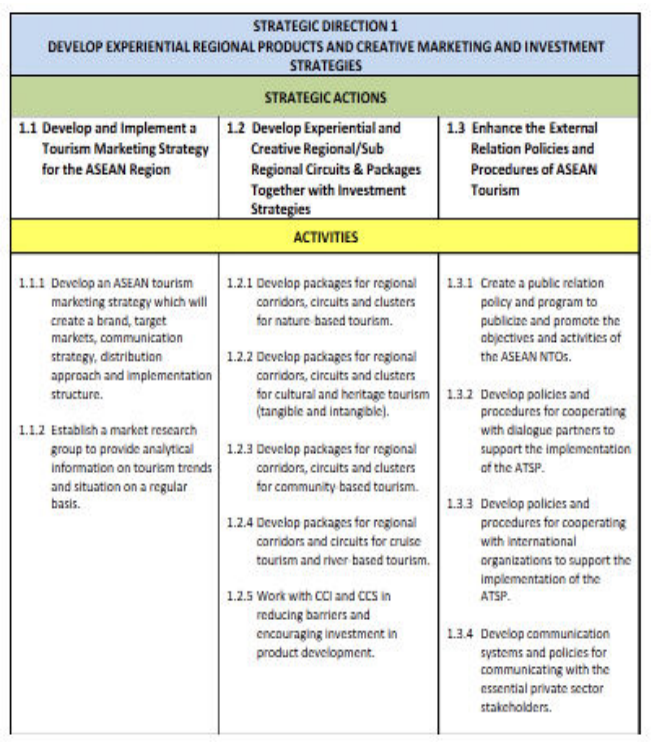

Sumber: ASEAN Tourism Strategic Plan 2011-2015

\section{Peningkatan kualitas pelayanan dan sumberdaya manusia ;}

Peningkatan kualitas pelayanan dan sumberdaya manusia merupakan arahan strategi kedua dari ATSP 2011-2015. Arahan kedua ini memliki tiga aksi strategis meliputi ;

1. Pengembangan seperangkat standar pariwisara asean dalam proses sertifikasi;

2. Pelaksanaan Mutual Recognition Arrangement (MRA) guna pariwisata ASEAN yang professional;

3. Pemberian Kesempatan untuk meningkatkan pengetahuan dan keterampilan pengembangan bagi masyarakat. $^{33}$

${ }^{32}$ Ibid,

Andalas Journal of International Studies | Vol 6 No 1 Mei Tahun 2017 
Haiyyu Darman Moenir | Implementasi ASEAN Tourism Strategic Plan 2011-2015 dalam Kebijakan Pariwisata Indonesia di masa Pemerinatahan Jokowi

Penjelasan signifikan akan dijabarkan dalam bentuk table yang dikutip dari

Arahan strategi ketiga ini lebih

ASEAN Tourism Strategic Plan 20112015 sebagai berikut :

\begin{tabular}{|c|c|c|}
\hline \multicolumn{3}{|c|}{$\begin{array}{c}\text { STRATEGIC DIRECTION2 } \\
\text { INCREASE THE QUALITY OF HUMAN RESOURCES, SERVICES AND FACILTIIES IN THE REGION }\end{array}$} \\
\hline \multicolumn{3}{|c|}{ STRATEGICACTIONS } \\
\hline $\begin{array}{l}\text { 2.1 Develop a Set of ASEAN } \\
\text { Tourism Standards with a } \\
\text { Certification Process }\end{array}$ & $\begin{array}{l}2.2 \text { Implement the MRA on } \\
\text { ASEAN Tourism Professionals } \\
\text { and its Requirements }\end{array}$ & $\begin{array}{l}\text { 2.3 Provide Opportunities for } \\
\text { Increased Knowledge and } \\
\text { Skill Development }\end{array}$ \\
\hline \multicolumn{3}{|c|}{ STRATEGICACTIVITIES } \\
\hline $\begin{array}{l}\text { 2.1.1. Revise and develop an ASEAN } \\
\text { green hotel standard with a } \\
\text { certification process. } \\
2.1 .2 \text { Revise and develop an ASEAN } \\
\text { homestay standard with a } \\
\text { certification process. } \\
\text { 2.1.3 Revise and develop an ASEAN } \\
\text { public toilet standard with a } \\
\text { certification process. } \\
\text { 2.1.4 Develop an ASEAN spa } \\
\text { services standard with a } \\
\text { certification process. } \\
\text { 2.1.5 Develop ASEAN tourism } \\
\text { security and safety guidelines. } \\
\text { 2.1.6 Enhance the ability of ASEAN } \\
\text { tourism to address the climate } \\
\text { change issue. }\end{array}$ & $\begin{array}{l}\text { 2.2.1 Develop tools and implement } \\
\text { human resource development } \\
\text { programs for housekeeping } \\
\text { division. } \\
\text { 2.2.2 Develop tools and implement } \\
\text { human resource development } \\
\text { programs for front office, } \\
\text { food and beverage services, } \\
\text { food production, travel } \\
\text { agencies and tour operation } \\
\text { divisions. } \\
\text { 2.2.3 Develop tools to monitor the } \\
\text { tourism labor market situation } \\
\text { in each ASEAN Member State } \\
\text { that would support the } \\
\text { implementation of MRA on } \\
\text { Tourism Professionals. }\end{array}$ & $\begin{array}{l}\text { 2.3.1 Establish policies and } \\
\text { procedures for the } \\
\text { development of capacity } \\
\text { building programs } \\
\text { (including the process to } \\
\text { be followed, assessment } \\
\text { systems and the criteria to } \\
\text { assess initiatives that will } \\
\text { get ASEAN backing.) } \\
\text { 2.3.2 Develop a yearly human } \\
\text { resource development } \\
\text { plan based on regional } \\
\text { priorities. }\end{array}$ \\
\hline
\end{tabular}
berfokus pada fasilitas yang diberikan dan keterbubungan satu sama lain guna percepatan hasil peningkatan pariwisata di negara-negara anggota ASEAN. Arahan strategi ini memiliki dua indikator aksi yakni;

1. Pengajuan mengenai visa tunggal untuk kawasan ASEAN ;

2. Kerjasama dengan badan-badan ASEAN yang relevan guna memperluas konektivitas. ${ }^{35}$

Aktivitas-aktivitas yang mendukung jalannya arahan dan aksi strategis dibagian ini juga dipaparkan secara jelas dalam tabel yang diambil dari sumber yang sama yakni ASEAN Tourism Strategic Plan 2011-2015. Penjelasan signifikan akan dijabarkan dalam bentuk table yang dikutip dari ASEAN Tourism Strategic Plan 2011-2015 sebagai berikut

Sumber: ASEAN Tourism Strategic Plan 2011-2015

\section{Peningkatan dan percepatan fasilitas pelayanan serta konetivitas ASEAN. ${ }^{34}$}

${ }^{34}$ ASEAN Tourism Strategic Plan 2011-2015, http://asean.org/?static post=asean-tourism-

strategic-plan-2011-2015-2 diakses pada 15 oktober 2016 pada pukul 08.06 wib

${ }^{35} \mathrm{Ibid}$, 
Haiyyu Darman Moenir | Implementasi ASEAN Tourism Strategic Plan 2011-2015 dalam Kebijakan Pariwisata Indonesia di masa Pemerinatahan Jokowi

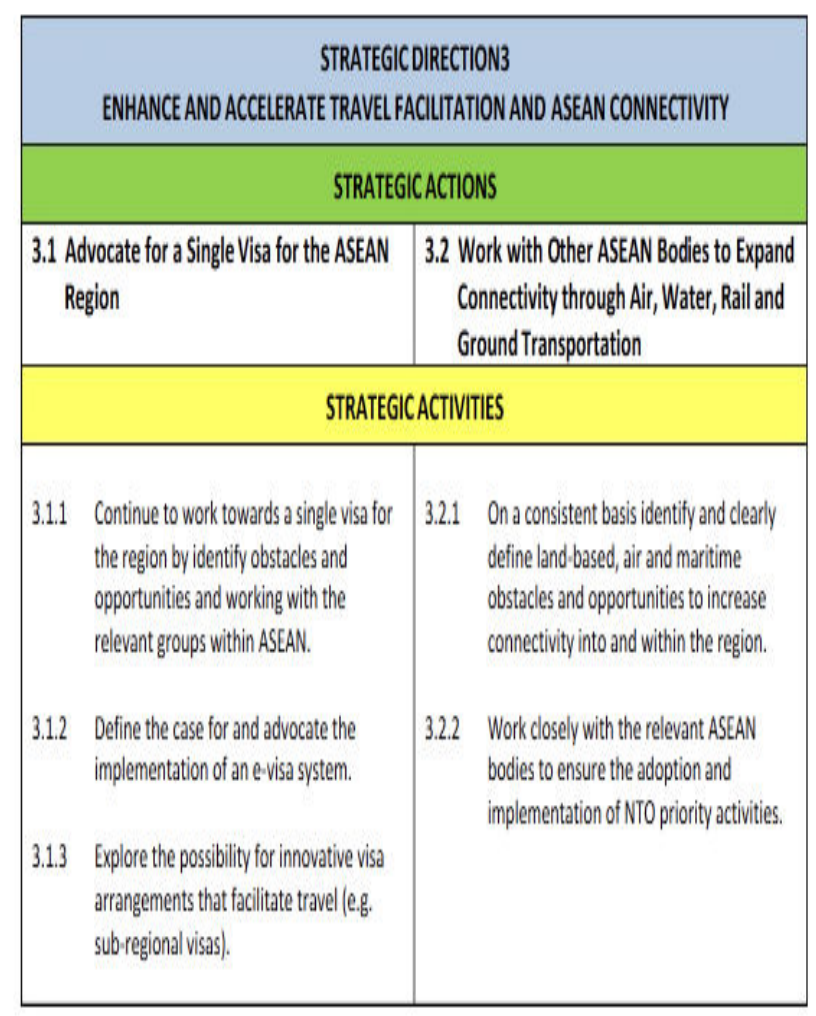

Sumber: ASEAN Tourism Strategic Plan 2011-

2015Implementasi ASEAN Tourism Strategic Plan 2011-2015 dalam Kebijakan Pariwisata Indonesia di masa Pemerintahan Jokowi

Pada pemaparan sebelumnya, sudah dijabarkan mengenai bentuk kongkrit dari ASEAN Tourism Strategic Plan 2011-2015 dengan elemen-elemen penjelas tentang arah strategi yang ingin dibentuk oleh ASTP 2011-2015. Pengembangan ide dalam tulisan ini juga didukung dengan data mengenai arah kebijakan pariwisata Indonesia di masa Pemerintahan Jokowi melalui penjabaran strategi dan arah kebijakan yang ingin dibentuk. Kedua data tersebut akan dijadikan landasan dasar analisis untuk melihat pengimplementasian ASEAN Tourism Strategic Plan 2011-2015 pada kebijakan pariwisata yang dibuat dimasa pemerintahan Jokowi.

Tulisan berangkat dari 3 arah strategi yang dimuat dalam ASEAN Tourism Strategic Plan 2011-2015 yang kemudian akan diturunkan kedalam kebijakan pariwisata yang dimiliki oleh Indonesia. Analisis ini meliputi :

\section{Implementasi Pengembangan Produk- produk kawasan dan pemasaran serta strategi investasi}

'Dalam arah strategi mengenai pengembangan produk kawasan dan pemasaran serta strategi investasi, ASEAN Tourism Strategic Plan 2011-2015 menurunkannya kedalam tiga poin dasar dianataranya Strategi pemasaran, Paket wisata kawasan dan sub-kawasan serta hubungan eksternal dan prosedur pariwisata ASEAN meliputi Investasi. ${ }^{36}$

\footnotetext{
${ }^{36}$ ASEAN Tourism Strategic Plan 2011-2015, http://asean.org/?static post=asean-tourismstrategic-plan-2011-2015-2 diakses pada 15 oktober 2016 pada pukul 08.06 wib
} 
Haiyyu Darman Moenir | Implementasi ASEAN Tourism Strategic Plan 2011-2015 dalam Kebijakan Pariwisata Indonesia di masa Pemerinatahan Jokowi

\section{Strategi pemasaran pariwisata untuk wilayah ASEAN}

Dalam poin ini terlihat bahwa strategi pemasaran pariwisata dimplementasikan oleh kebijakan pariwisata Indonesia melalui dua poin pengembangan pembangan pemasaran pariwisata Indonesia yang meliputi pengembangan pemasaran pariwisata mancanegara dan pengembangan pariwisata pariwisata Nusantara. 37 Pengembangan stretegi pemasaran pariwisata Indonesia yang dibagi menjadi dua jenis yakni mancanegara dan nusantara juga memiliki poin-poin pengembangan tersendiri. Pada pengembangan pemasaran pariwisata mancanegara, pemerintah lebih menekankan pada peningkatan citra kepariwisataan, mengembangan strategi dan komunikasi pemasaran sesuai dengan fokus pasar bersadarkan wilayah yang salah satunya dalah negara-negara dikawasan Asia Tenggara. Selain itu, peningkatan promosi produk wisata baik wisata alam, budaya maupun buatan juga menjadi fokus dalam pengembangan pemasran parwisata Indonesia di tingkat Mancanegara. ${ }^{38}$

\footnotetext{
${ }^{37}$ Kementrian Pariwisata Republik Indonesia

"Rencana Strategis Kementrian Pariwisata tahun 2011-2019”. Hal 109-115

${ }^{38}$ Ibid,
}

Pada pengembangan pemasaran pariwisata nusantara, pemerintah lebih menekankan kepada peningkatan jumlah segmen pasar personal, segmen pasar bisnis dan pemerintah melalui tiga produk utama yakni wisata alam yang terdiri dari wisata bahari, wisata ekologi, dan wisata petualangan. Wisata budaya yang terdiri dari wisata heritage dan religi, wisata kuliner dan belanja, dan wisata kota dan desaserta Wisata ciptaan yang terdiri dari wisata MICE \& Event, wisata olahraga, dan wisata kawasan terpadu.

Paket wisata kawasan dan sub-kawasan

Pada bagian ini pengembangan paket wisata kawasan dan sub-kawasan, terlihat bahwa pemerintah Indonesia mengimplementasikan bagian ini melalui kebijakan pengembangan destinasi dan industri pariwisata. Dalam pengembangan destinasi dan industri pariwisata, ada beberapa indikator yang digunakan antara lain adalah Pembangunan Infrastruktur dan Ekosistem Pariwisata meliputi perancangan destinasi pariwisata (kawasan strategis pariwisata nasional dan kawasan pengembangan pariwisata nasional). ${ }^{39}$

${ }^{39}$ ibid, Hal 109 
Haiyyu Darman Moenir | Implementasi ASEAN Tourism Strategic Plan 2011-2015 dalam Kebijakan Pariwisata Indonesia di masa Pemerinatahan Jokowi

Peningkatan aksesibilitas, atraksi, amenitas, dan ekosistem pariwisata serta Pengembangan Destinasi Wisata alam, budaya, dan buatan meliputi Pengembangan wisata kuliner dan spa, wisata sejarah dan religi, wisata tradisi dan seni budaya, wisata perdesaan dan perkotaan, serta Pengembangan wisata bahari, wisata ekologi dan petualangan, kawasan pariwisata terpadu, serta wisata konvensi, olahraga dan rekreasi juga di indikasikan sebagai sebuah bentuk implemantasi dari pengembangan paket wisata kawasan dan sub-kawasan.

Dalam pengembangan kepariwisataan Indonesia, Presiden Joko Widodo dalam kebijakan pariwisata memusatkan perhatian pada pengembangan 10 destinasi yang dianggap akan menjadi sektor paling memberikan kontribusi besar pariwisata Indonesia. 10 lokasi destinasi wisata yang menjadi fokus prioritas antara lain adalah;

1. Danau Toba di Sumatera Utara

2. Tanjung Kelayang di Bangka Belitung

3. Kpulauan seribu di DKI Jakarta

4. Tanjung lesung di Banten

5. Borobudur di Jawa Tengah

6. Bromo Tengger semeru di jawa timur
7. Madalika di Nusa Tenggara Barat

8. wakatobi di Sulawesi Tenggara

9. Pulau Morotai di Maluku utara

10. Pulau komodo di Nusa Tenggara Timur. $^{40}$

Dengan fokus pada pengembangan destinasi wisata baru, diharapkan nantinya pola pikir mengenai Indonesia hanyalah Bali mampu di ubah dengan membentuk pola pikir baru bahwa Indonesia memiliki balibali lain nya yang tidak kalah dengan Bali yang sebenarnya. dengan mengembangkan destinasi baru ini, diharapkan nantinya pariwisara Indonesia mampu berkembang lebih pesat dari sebelumnya.

\section{Peningkatan Hubungan Eksternal dan Prosedur Pariwisata; strategi investasi}

Pada bagian ini akan melihat bagaiamana hubungan eksternal yang dibangun serta strategi investasi yang dilakukan oleh Indonesia melalui kebijakan yang dibuat dibagian Pengembangan pariwisata yang diturunkan kedalam pengembangan industry pariwisata tentang peningkatan kemitraan usaha pariwisata

${ }^{40}$ Slide persentasi mengenai "Strategi Pengembangan Keparwisataan Indonesia” dipaparkan oleh Dadang Rizki Ratman,SH.M.PA, 
Haiyyu Darman Moenir | Implementasi ASEAN Tourism Strategic Plan 2011-2015 dalam Kebijakan Pariwisata Indonesia di masa Pemerinatahan Jokowi

serta investasi dibidang pariwisata. Peningkatan hubungan ekseternal dijelaskan dalam kebijakan Indonesia dalam bidang pariwisata adalah mengenai peningkatan kemitraan usaha yang dilakukan dibidang pariwisata itu sendiri melalui kemitraan dengan pihak-pihak yang dianggap mumpuni dan memiliki arah kemajuan bersama di bidang pariwisata Indonesia. Diharapkan nantinya kemitraan yang terjalin akan memberikan dampak positif dalam bentuk investasi guna pengembangan bidang pariwisata yang semakin maju.

\section{Peningkatan Kualitas Pelayanan dan Sumber Daya Manusia}

Peningkatan kualitas pelayanan dan sumberdaya manusia menjadi poin kedua dalam pelaksanaan ASEAN Tourism Strategic Plan 2011-2015. Pembahasan mengenai bagian ini diturunkan kedalam tiga elemen utama yakni pengembangan seperangkat standar pariwisata ASEAN dalam proses sertifikasi, Pelaksanaan Mutual Recognition Arrangement (MRA) guna pariwisata ASEAN yang profesional, serta pemberian kesemparan untuk meningkatkan pengetahuan dan keterampilan pengembangan masyarkat.

Indonesia melalui kebijakan pariwisata menekankan pada pengembangan sumberdaya manusia yang diharapkan bisa menjadi salah satu komponen yang mempercepat jalannya pengembangan pariwisara Indonesia. pengembangan sumberdaya manusia dimasukkan dalam program yang mencakup seluruh provinsi di Indonesia agar pengembangan pariwisata mampu merata kesua daerah di Indonesia. Pengembangan pariwisata ini meliputi:

1. sertifikasi kompetensi SDM di bidang pariwisata di 34 provinsi di Indonesia

2. peningkatan kualitas SDM aparatur kementrian pariwisata dan pelatihan dasar SDM bidang pariwisata di 34 Provinsi

3. Peningkatan kualitas lulusan pendidikan tinggi pariwisata yang 100\% terserap di pasar kerja dan seleksi masuk sekolah tinggi, akademi dan politeknik pariwisata (SBM-STAPP) $)^{41}$

${ }^{41}$ Ibid. 
Haiyyu Darman Moenir | Implementasi ASEAN Tourism Strategic Plan 2011-2015 dalam Kebijakan Pariwisata Indonesia di masa Pemerinatahan Jokowi

\section{Pengembangan seperangkat standar pariwisata ASEAN dalam proses sertifikasi}

Pada bagian ini setidaknya ada dua elemen besar dari kebijakan Indonesia mengenai pariwisata yang mendukung berjalannya pengembangan seperangkat standar pariwisata ASEAN dalam proses sertifikasi. Elemen tersebut meliputi pengembangan destinasi dan industri pariwisata yang diturunkan kedalam kebijakan pengembangan industri pariwisata yang meliputi Pengembangan standar dan sertifikasi usaha pariwisata serta peningkatan keragaman dan daya saing produk jasa pariwisata di setiap destinasi pariwisata.

Elemen kedua adalah pengembangan dukungan manajemen yang diturunkan kedalam tiga poin utama antara lain Peningkatan kualitas layanan pusat informasi dan peningkatan aktivasi saluran media sosial (Social Media), seperti: facebook, twitter, instagram, path dan youtube. Poin kedua adalah Peningkatan kualitas kinerja pengelolaan APBN Kementerian Pariwisata menuju status WTP (Wajar Tanpa Pengecualian). Dan poin ketiga meliputi peningkatan sarana dan prasarana Kementerian Pariwisata.

\section{Pelaksanaan Mutual Recognition Arrangement (MRA) Guna Pariwisata ASEAN Yang Profesional}

Pada elemen kedua dari pengembangan seperangkat standar pariwisata ASEAN dalam proses sertifikasi, tidak ditemukan secara implisit mengenai turunan poin ini didalam kebijakan pariwisata yang dibuat pada masa pemerintaan Jokowi.

\section{Pemberian Kesempatan untuk meningkatkan pengetahuan dan keterampilan pengembangan bagi masyarakat}

Bagian ini menjadi elemen yang sangat penting dalam pengembangan pariwisata, karena dengan dukungan sumberdaya manusia yang memadai dan mumpuni untuk sektor pariwisata, pengembangan pariwisata akan sangat mudah dilakukan hingga memberikan dampak yang sangat signifikan baik di sektor domestik maupun regional serta internasional. Indonesia dengan arah kebijakan pariwisatanya, cukup memberikan peluang besar didalam pengembangan sumberdaya manusia baik di masyarakat 
Haiyyu Darman Moenir | Implementasi ASEAN Tourism Strategic Plan 2011-2015 dalam Kebijakan Pariwisata Indonesia di masa Pemerinatahan Jokowi

awam maupun profesional yang berkecimpung langsung dibidang pariwisata itu sendiri. Pengimplementasian mengenai elemen ini terdapat didalam Pengembangan destinasi dan industry pariwisata yang diturunkan kedalam peningkatan tata kelola destinasi pariwisata dan pemberdayaan masyarakat dengan melalui peningkatan sadar wisata pada masyarakat serta pengembangan potensi usaha masyarakat di bidang pariwisata.

Dibagian lain, elemen ini juga diimplementasikan oleh Indonesia melalui pengembangan kelembagaan pariwisata yang dimuat dalam beberapa poin yakni optimalisasi kegiatan penelitian dan pengembangan sebagai pijakan arah kebijakan kepariwisataan, peningkatan kompetensi tenaga kerja kepariwisataan melalui sertifikasi kompetensi, peningkatan kualitas dan kuantitas lulusan Perguruan tinggi pariwisata, peningkatan kompetensi SDM aparatur kepariwisataan, serta Pendirian lembaga diklat pariwisata.

\section{Peningkatan dan percepatan fasilitas dan pelayanan serta konektivitas ASEAN}

Elemen ini membawahi dua poin besar yakni pengajuan mengenai visa tunggal untuk kawasan ASEAN serta kerjasama dengan badan-badan yang relevan guna memperluas konektivitas. Dua poin besar ini akan dijelaskan lebih mendalam melalui penjabaran sebagai berikut.

\section{Pengajuan mengenai visa tunggal untuk kawasan ASEAN}

Sebagai kawasan yang mencoba untuk mengembangkan komunitas dan mewujudkan konektivitas yang semakin erat, ASEAN melalui ASEAN Tourism Strategic Forum 2011-2015 mengajukan perencanaan untuk pembentukan visa tunggal bagi kawasan ASEAN, hanya saja implementasi ini masih dalam tahapan rencana. Indonesia sendiri tidak memiliki arah kebijakan yang terfokus untuk mengimplementasikan visa tunggal ASEAN. Hanya saja setiap negara ASEAN sudah mengimplementasikan dan melaksanakan bebas Visa kunjungan wisata bagi warga negara dari negara ASEAN untuk berkunjung ke berbagai negara ASEAN dengan limitasi waktu yang ditentukan oleh masing-masing negara ASEAN. 
Haiyyu Darman Moenir | Implementasi ASEAN Tourism Strategic Plan 2011-2015 dalam Kebijakan Pariwisata Indonesia di masa Pemerinatahan Jokowi

\section{Kerjasama Dengan Badan-Badan ASEAN Guna Memperluas Konektivitas}

Elemen ini didukung baik oleh Indonesia dengan membuat sebuah kebijakan pariwisata yang berindikasi pada pengembangan kelembagaan yang diturunkan kedalam pengembangan hubungan kelembagaan kepariwisataan di tingkat nasional maupun internasional.

\section{Kesimpulan}

Sektor pariwisata Indonesia dimasa pemerintahan presiden Joko Widodo merupakan salah satu dari lima sektor priotitas utama pemerintah dalam kemajuan dan pengembangan bangsa Indonesia. Kebijakan yang dipilih dalam sektor pariwisata juga didasarkan pada keinginan guna pencapatarget-terget pengembangan pariwisata menjadi lebih baik. Salah satu acuan yang digunakan dalam perumusan kebijakan parwisata Indonesia adalah melalui pengimplementasian ASEAN Tourism Strategic Plan 2011-2015 kedalam kebijakan domestik Indonesia di bidang pariwisata.

Pengimplementasian ini tampak jelas dengan komponen-komponen kebijakan yang memiliki kesamaan dengan ASEAN Tourism Strategic Plan 2011-2015.
Pengimplementasian kebijakan tersebut meliputi Implementasi pengembangan produk kawasan dan pemasaran serta strategi invstasi yang kemudian diturunkan dalam strategi pemasaran pariwisata ASEAN, strategi pemasaran ini kemudian dijadikan acuan dalam kebijakan pariwisata Indonesia dengan membuat strategi pemasaran mancanegara dan strategi pemasaran Nusantara.

Jika dalam ASEAN Tourism Strategic Plan 2011-2015 di bahas tentang pengembangan paket wisata kawasan dan sub kawasan, dalam kebijakan Indonesia diturunkan kedalam pengembangan destinasi dan industry pariwisata yang meliputi pengembangan infrastruktir dan ekosistem pariwisata, pengembangan destinasi wisata alam, budaya dan buatan, serta pengembangan industry pariwisata itu sendiri melalui peningkatan keberagaman dan daya saing produk jasa pariwisata di setiap destinasi pariwisata.

Peningkatan hubungan eksternal dan prosedur melalui strategi investasi diimplementasikan oleh Indonesia melalui peningkatan kemitraan usaha pariwisata da investasi di bidang pariwisata. Arahan kedua pada ATSP ASEAN Tourism Strategic Plan 
Haiyyu Darman Moenir | Implementasi ASEAN Tourism Strategic Plan 2011-2015 dalam Kebijakan Pariwisata Indonesia di masa Pemerinatahan Jokowi

2011-2015, dibunyikan mengenai peningkatan kualitas pelayanan dan sumberdaya manusia. Indonesia mengimlementasikan poin ini kedalam pengembangan standard an sertifikasi usaha pariwisata serta dukungan managerial mulai dari peningkatan layanan pusat informasi, peningkatan kinerja pengelola pariwisata serta peningkatan saran dan prasarana kementrian pariwisata. Pemberdayaan masyarakat dengan peningkatan masyarakat sadar wisata dan pengembangan potensi usaha masyarakat juga menjadi kebijakan yang dikembangkan Indonesia guna pengembangan masysarakat agar mampu mendukung jalannya percepatan pembangunan Indonesia.

Sedangkan yang ketiga adalah mengenai peningkatan dan percepatan fasilitas pelayanan serta konektivitas ASEAN dilakuka dengan pengembangan hubungan kelembagaan kepariwisataan di tingkat nasional dan internasional.

Dari sekian banyak poin penjabaran diatas, mampu disimpulkan bahwa 80 persen dari ASEAN Tourism Strategic Plan 20112015 telah diimplementasikan oleh Indonesia dalam bentuk kebijakan pariwisata guna percepatan pertumbuhan ekonomi dan perbaikan pariwisata Indonesia. Hanya ada dua poin yang belum terimplementas nyata oleh kebijakan pariwisata Indonesia antara lain adalah Pelaksanaan Mutual Recognition Arrangement (MRA) guna pariwisata ASEAN yang profesional dan pengajuan mengenai visa tunggal untuk kawasan ASEAN.

\section{Daftar Pustaka}

Amalia, Lady. Efektivitas ASEAN Torism Strategic Plan 2011-2015 di Indonesia, Jurnal Analisis Hubungan Internasional, Vol. 5 No. 1. 2016

Anonim. 2014c. "Perkenalkan Poros Maritim: Presiden Joko Widodo Dijadwalkan Jadi Pembicara Utama di APEC" dalam Harian Kompas, No. 126 Tahun ke-50, 6 November 2014.

Anonim. 2014e. "Di EAS, Jokowi Beberkan Lima Pilar Poros Maritim Dunia" dalam www.antaranews.com yang diakses pada 23 November 2014.

APCO. 2014. "A Jokowi Presidency: Politics, Government and Business Under Indonesia's Future President"dalam APCO Worldwide, 24 Juli 2014.

Aziz, Munawir. 2014. "Tantangan Poros Maritim Jokowi" dalam Harian Suara Merdeka, 18 Oktober 2014.

Chheang, Vannarith."Tourism and Regional Integrastion in Southeast Asia",Tokyo: IDE-JETRO,2013 
Haiyyu Darman Moenir| Implementasi ASEAN Tourism Strategic Plan 2011-2015 dalam Kebijakan Pariwisata Indonesia di masa Pemerinatahan Jokowi

Chuvyers, Ludo dan Wisarn Pupphavesa. 1996. From ASEAN to AFTA, CAS Discussion Paper No. 46.

Direktorat Jenderal Kerjasama ASEAN Republik Indonesia. 2009. "Cetak Biru Komunitas Ekonomi ASEAN 2015”, hal. 7

Direktorat Jenderal Pendidikan Tinggi Kementerian Pendidikan dan Kebudayaan, 2012. "Panduan Penelitian Prioritas Nasional Masterplan Percepatan Dan Perluasan Pembangunan Ekonomi Indonesia 2011-2025 (Penprinas Mp3ei 20112025)”. Hal. 1

Hikmat, Harry. 1995. “ Paradigma Pembangunan dan Implikasi dalam perencanaan Sosial" Jakarta: Universitas Indonesia.

Holsti , K.J. National Role Conceptions in the Study of Foreign Policy (International Studies Quarterly, Vol. 14, No. 3. Blackwell Publishing on behalf of The International Studies Association. 1970

Inskeep, Edward. 1991. Tourism Palinning : Integrated and Sustainable development Approach, Van Nostrand Reinhold, New York.Kementrian Pariwisata Republik Indonesia. Rencana Strategis Kementrian Pariwisata tahun 2011-2019.

Kementerian Pariwisata dan Ekonomi Kreatif Republik Indonesia. 2012. Rencana Strategis 2012-2014. Jakarta: Kementerian Pariwisata dan Ekonomi Kreatif Republik Indonesia.
Kementerian Pariwisata dan Ekonomi Kreatif Republik Indonesia. 2012. Rencana Strategis Direktorat Jenderal Pengembangan Destinasi Pariwisata 2012-2014. Jakarta: Direktorat Jenderal Pengembangan Destinasi Pariwisata Kementerian Pariwisata dan Ekonomi Kreatif Republik Indonesia.

KPU. (2014b). "Jalan Perubahan Untuk Indonesia yang Berdaulat, Mandiri dan Berkepribadian: Visi, Misi, dan Program Aksi Jokowi-Jusuf Kalla 2014" dalam www.kpu.go.id, yang diakses 23 November 2014.

Lesnussa, Nurhayati. Pengaruh Citra Keamanan Nasional Indonesia terhadap Jumlah Wisatawan di Indonesia (Studi Kasus : Indonesia Visit Year 2008. 2009

Lumaksono, Adi, et al. 2012. Dampak Ekonomi Pariwisata Internasional Pada Perekonomian Indonesia. Forum Pascasarjana Vol. 35 No. 1, 53-68.

Marsetio. 2014. Sea Power Indonesia. Jakarta: Universitas Pertahanan.

Mclntyre, George. 1993. Sustainable Tourism Development : Guide for Local Planners, WTO, Spain.

Muhamad, Simela Victor. (2014). "Indonesia Menuju Poros Maritim Dunia" dalam Info Singkat Hubungan Internasional, Vol. VI, No. 21/I/P3DI/November/2014.

OECD. 2014. The OECD Economic Outlook, Vol. 2014/1. Paris: OECD Publishing. 
Haiyyu Darman Moenir | Implementasi ASEAN Tourism Strategic Plan 2011-2015 dalam Kebijakan Pariwisata Indonesia di masa Pemerinatahan Jokowi

Peraturan Pemerintah No. 50 tahun 2011 tentang Rencana Induk Pembangunan Kepariwisataan Nasional (RIPPARNAS) Tahun 2010-2025

Prayini, Is. Pengaruh Destination Branding terhadap Tourist Retention Pada Wisatawan Indonesia yang berkunjung ke Thailand. Bandung: Universitas Pendidikan Indonesia, 2013

Primayoga, Fandy Meirizma, Analisis Kebijakan Indonesia Terkait Dukungan Terhadap ASEAN Insfrastruktur Fund Sebagai Upaya Persiapan Pelaksanaan ASEAN Economic Community 2015. Malang: Universitas Brawijaya, 2013

Ripley \& Franklin. 1992. Policy Implementation and Bureaucracy. The Dorsey Press, Chicago, hal 4. Dapat diakses pada http://lontar.ui.ac.id/file?file=digital/1 19393-T\%2025259-

Implementasi\%20kebijakanLiteratur.pdf (akses 28 Januari 2014)

Rosenau, James N. 1981. The Study of Political Adaptation: Essays on the Analysis of World Politics. New York: Nichols Publishing.

Sofield, "Rethinking and reconceptualizing social and culture in southeast and south asian tourism development", Oxford:Butterworth Heinemann, 2000

Spillane, James J., 1991, Ekonomi Pariwisata : Sejarah dan Prospeknya, Yogyakarta : Kanisius.

Thorson, Stuart J. 1973. "Adaptation and Foreign Policy Theory" dalam Sage
International Yearbook of Foreign Policy Studies Research Paper No. 18. Wahyudi, H. Pariwisata, Pengentasan Kemiskinan, dan MDGs. Denpasar: UPBJJ, 2012

\section{Website:}

ASEAN Secretariat, ASEAN Vision 2020, ASEAN Secretariat, Jakarta, 15 December 1997 (www.aseansec.org/2357.htm)

ASEAN Secretary. Master Plan on ASEAN Connectivity.Jakarta: Asean Secretary, 2011

ASEAN Secretary. Tourism Strategic Plan 2011 - 2015. Jakarta: ASEAN.

ASEAN Community in Figures (ACIF), 2011.

BPPK ASPASAF. ASEAN Connectivity in Indonesian Context. Jakarta: Kementerian Luar Negeri RI. 2011

World Economic Forum. 2011. The Travel \& Tourism Competitiveness Report 2011. Geneva: World Economic Forum.

World Tourism \& Travel Council. 2012. Travel \& Tourism Economic Impact 2012 Indonesia. 25 Mei 2013. London: World Tourism \& Travel Council. 